\title{
Does the use of a novel self-adhesive flowable composite reduce nanoleakage?
}

This article was published in the following Dove Press journal:

Clinical, Cosmetic and Investigational Dentistry

27 March 2015

Number of times this article has been viewed

\begin{abstract}
Abeer Abo El Naga'
Mohammed Yousef'

Rasha Ramadan ${ }^{2,3}$

Sherif Fayez Bahgat ${ }^{4,5}$

Lana Alshawwa ${ }^{6}$

'Operative Dentistry Department, Faculty of Dentistry, King Abdulaziz University, Jeddah, Saudi Arabia; ${ }^{2}$ Operative Dentistry Department, Modern Science and Arts University, Cairo, Egypt; ${ }^{3}$ Operative Dentistry Department, Dentistry Program, Batterjee Medical College, Jeddah, Saudi Arabia; ${ }^{4}$ Fixed Prosthodontics Department, Modern Science and Arts University, Cairo, Egypt;

${ }^{5}$ Fixed Prosthodontics Department, Dentistry Program, Batterjee Medical College, Jeddah, Saudi Arabia; ${ }^{6}$ Medical Education Department, Faculty of Medicine, King Abdulaziz University, Jeddah, Saudi Arabia
\end{abstract}

Correspondence: Mohammed Yousef Department of Operative Dentistry, Faculty of Dentistry, King Abdulaziz University, PO Box 80209, Jeddah 21589, Saudi Arabia

Tel/fax +966 I2 6403443 ext 21012

Email myousf@kau.edu.sa
Objective: The aim of the study reported here was to evaluate the performance of a self-adhesive flowable composite and two self-etching adhesive systems, when subjected to cyclic loading, in preventing the nanoleakage of Class $\mathrm{V}$ restorations.

Methods: Wedge-shape Class V cavities were prepared $(4 \times 2 \times 2 \mathrm{~mm}$ [length $\times$ width $\times$ depth]) on the buccal surfaces of 90 sound human premolars. Cavities were divided randomly into three groups $(n=30)$ according to the used adhesive (Xeno ${ }^{\circledR} \mathrm{V}$ [self-etching adhesive system]) and BOND- ${ }^{\circledR}$ SF (solvent-free self-etching adhesive system) in conjunction with Artiste ${ }^{\circledR}$ Nano Composite resin, and Fusio ${ }^{\mathrm{TM}}$ Liquid Dentin (self-adhesive flowable composite), consecutively. Each group was further divided into three subgroups (n=10): (A) control, (B) subjected to occlusal cyclic loading ( $90 \mathrm{~N}$ for 5,000 cycles), and (C) subjected to occlusal cyclic loading ( $90 \mathrm{~N}$ for 10,000 cycles). Teeth then were coated with nail polish up to $1 \mathrm{~mm}$ from the interface, immersed in 50\% silver nitrate solution for 24 hours and tested for nanoleakage using the environmental scanning electron microscopy and energy dispersive analysis X-ray analysis. Data were statistically analyzed using two-way analysis of variance and Tukey's post hoc tests $(P \leq 0.05)$.

Results: The Fusio Liquid Dentin group showed statistically significant lower percentages of silver penetration $(0.55 \mu)$ compared with the BOND-1 SF $(3.45 \mu)$ and Xeno V $(3.82 \mu)$ groups, which were not statistically different from each other, as they both showed higher silver penetration.

Conclusion: Under the test conditions, the self-adhesive flowable composite provided better sealing ability. Aging of the two tested adhesive systems, as a function of cyclic loading, increased nanoleakage.

Keywords: Class V, flowable composite, nanoleakage, cyclic loading, self-adhesive

\section{Introduction}

Class V cavities are mainly caused by dental caries and incorrect brushing technique, and usually are deprived of enamel at the margins located cervically. Recently, flowable composite resins have become very appealing to daily practice and are usually recommended for the restoration of these cavities as an effective replacement for conventional composite resin restorative materials. These materials are superior in esthetic properties and have low viscosity, ${ }^{1-3}$ which makes them easier to place and more self-adaptable than conventional resin composites. ${ }^{4,5}$ Also, flowable materials are widely used as gingival liners in Class II composite resin restorations, as they may act as stress breakers. Unfortunately, these materials have a higher rate of polymerization shrinkage, a higher coefficient of thermal expansion, ${ }^{6,7}$ and inferior mechanical properties, ${ }^{3}$ which is due to their lower filler content. Polymerization 
shrinkage creates stresses that adversely affect the adhesive bond, and decrease the bond to cavity walls, and is thus considered one of the main reasons for microleakage and, subsequently, marginal failure. ${ }^{6-8}$ The lack of enamel at the gingival margin in cervical lesions is a big challenge. ${ }^{9}$ Moreover, the importance of a perfect seal for the success and longevity of Class $\mathrm{V}$ resin restorations should be taken into consideration at the restorative treatment time. ${ }^{2,10}$ Miyasaka and Okamura found that the shrinkage ratio was less than $1.5 \%$ in conventional composites, but more than $2.0 \%$ in flowable ones. ${ }^{1}$ Nevertheless, some studies have shown that, compared with hybrid composites, flowable composite resins exhibit similar polymerization contraction stresses. ${ }^{11,12}$

Ideally, adhesive systems should bond evenly with both enamel and dentin without being technique sensitive. ${ }^{13}$ However, this is not the case in composite restorations, where the bonding to enamel varies from that to dentin, with the former still believed to be more reliable than the latter, ${ }^{14,15}$ as reduction in micro- and nanoleakage is obvious, but not yet completely eliminated. ${ }^{16,17}$

For many years, the longevity of bonded restorations has been expressed in terms of microleakage extent measurements. ${ }^{18}$ This leakage around resin composite restoration decreases restoration longevity, as it might lead to postoperative sensitivity, marginal discoloration, secondary caries, pulpal inflammation, and eventually partial or complete loss of that restoration. ${ }^{19,20}$ However, the latter may be due to either imperfections or improper cavity preparation. "Nanoleakage", which is a different pattern of leakage occurring within the hybrid layer in nanometerscaled spaces, ${ }^{21}$ may be due to the presence of residual water around collagen fibrils, collagen network collapse, or incomplete resin infiltration into the exposed collagen network and polymerization. ${ }^{22}$ This pattern may arise within the adhesive layer and likewise within the hybrid layer, ${ }^{23}$ causing bacterial product or oral fluid penetration across the interface, compromising the stability of the resin-dentin bond through hydrolytic breakdown of the adhesive resin or collagen in the hybrid layer. ${ }^{24}$ Therefore, nanoleakage assessment could be considered an important indicator of the sealability of a restorative material ${ }^{25}$ and hybrid-layer quality, which consequently affect the longevity of the restoration. $^{26}$

Nowadays, efforts are being made to simplify and shorten bonding procedures ${ }^{27}$ while retaining the effectiveness of dentin adhesives. Self-etching adhesive systems were developed to eliminate operator variables and minimize clinical operating time. ${ }^{28}$ Self-etching adhesive systems use acidic adhesive comonomers that simultaneously demineralize and infiltrate the dentin. ${ }^{29}$ All-in-one single-bottle self-etching adhesive systems were then introduced, combining etching, priming, and bonding in a single bottle. ${ }^{30}$ Owing to the fact that these single-bottle systems are highly hydrophilic polymers, which means they are permeable to water movement, it was claimed they were the most promising adhesive approach. ${ }^{31}$ Following this, solvent-free self-etch adhesive was introduced, with the solvent that is contained in all other adhesive systems having been removed. ${ }^{32}$ This adhesive has made it possible to create an interactive ionic bond between the tooth minerals and the resins of the bonding agent ${ }^{32,33}$ without the use of water, acetone, or alcohol. More recently, self-adhering flowable composite was introduced to address the time-consuming procedure used with traditional materials. ${ }^{34}$ Self-adhering flowable composite combines the merits of both adhesive and restorative material technologies in one product, bringing novel horizons to restorative techniques, as it is a direct composite resin restorative material that has an adhesive resin together with a flowable composite resin. ${ }^{35}$ It is based on the bonding technology that uses glycerophosphate dimethacrylate (GPDM) ${ }^{36}$ to etch enamel and dentin, and hydroxyethyl methacrylate (HEMA) to enhance wetting and penetration by resin into dentin. This resin bonds chemically between the phosphate groups of a GPDM monomer and the hydroxyapatite of tooth structure and, also, micromechanically between the polymerized monomers of the self-adhering flowable composite resin and the collagen fibers and smear layer of dentin. ${ }^{35,37}$

During normal function and parafunctional habits, teeth are subjected to stresses. ${ }^{38}$ Food bolus can induce vertical loading between antagonistic teeth, which is equally disseminated over the entire occlusal surface to alleviate stresses. ${ }^{39}$ Compressive stresses arise on the tooth aspect being bent, while tensile stresses are generated simultaneously on the opposite tooth aspect. ${ }^{40}$ The same scenario occurs with restorations placed cervically in teeth when those teeth are subjected to occlusal loading, which may lead to dislodgement of such restorations at their cavo-surface margin. ${ }^{41}$ Thus, the integrity of the margins of resin composite restorations is highly affected by cyclic loading, in terms of leakage. ${ }^{42}$

Unfortunately, as long-term clinical trials are impractical due to the constant evolution of new adhesive systems and restorative materials, the in vitro simulation of masticatory forces is necessary to study the effect of cyclic loading on nanoleakage at the resin-dentin interface. ${ }^{43}$ Moreover, the outcome of increased cyclic loading on the nanoleakage of different adhesive systems used in cervical 
composite restorations has not been yet fully analyzed. Therefore, the study reported here aimed to compare the sealability of self-adhesive flowable composite with that of two Class V composite restoration adhesive systems, to evaluate the longevity of the composite restoration seal in response to mechanical stresses and to assess the effect of increasing the number of load cycles, in terms of nanoleakage.

\section{Materials and methods Preparation of the cavities}

A total of 90 intact, non-carious human premolars, extracted for orthodontic reasons, were utilized in this research. Before any treatment, teeth were cleaned, explored, uncontaminated with chloramine-T compound, and cool-stocked, to be used within a maximum period of 1 month following their extraction. Wedge-shaped Class V cavity preparation was performed on the buccal surface of each tooth, with half of the cavity above the cementoenamel junction and the other half below it. ${ }^{9}$ For the purposes of standardization, a stainless-steel matrix band, with a window simulating the desired prepared cavity in width and length, was used in order for all cavity preparations to have uniform dimensions of $4 \mathrm{~mm}$ occlusogingival height and $2 \mathrm{~mm}$ mesiodistal width. Finally, the depth was set at 2 $\mathrm{mm}$, and this was checked in each cavity using a calibrated periodontal probe.

Class V cavity specimens were prepared for this study for four reasons. First, this type of cavity involves different dental hard structures, enamel, dentin, and cementum. Second, a Class V cavity simulates the clinical situation of higher stress due to higher C-factor. Third, to make the studies of adhesive systems more relevant, since samples prepared in this manner involve the difficulties in achieving the suggestive width of the adhesive layer with a higher $\mathrm{C}$-factor and higher stress contraction area. ${ }^{29,44}$ Finally, the corresponding restorative procedure concerning Class $\mathrm{V}$ lesions is minimal and comparatively simple, thus lowering, to a great extent, operator variability. ${ }^{45}$

\section{Grouping of the specimens}

Teeth were subjected to random division into three equal groups $(n=30)$ according to the tested adhesive materials (Table 1): cavity walls were treated either with $\mathrm{Xeno}^{\circledR} \mathrm{V}$ self-etching adhesive system (Dentsply Caulk, Milford, DE, USA) (Group 1), or BOND-1 ${ }^{\circledR}$ SF solvent-free self-etching adhesive system (Pentron Clinical, Orange, CA, USA) (Group 2), and then filled with Artiste ${ }^{\circledR}$ Nano Composite resin (Pentron Clinical) using oblique incremental technique, or restored directly with Fusio ${ }^{\mathrm{TM}}$ Liquid Dentin self-adhesive flowable composite (Pentron Clinical) (Group 3), according to manufacturers' instructions. After restoration of the cavities, each group was further subdivided into three equal subgroups $(\mathrm{n}=10)$ : Subgroup 1 - control, Subgroup 2 subjected to occlusal cyclic loading ( $90 \mathrm{~N}$ for 5,000 cycles), and Subgroup 3 - subjected to occlusal cyclic loading (90N for 10,000 cycles) (Table 2).

\section{Cyclic loading}

Aluminum foil was used to cover the root and the restoration of each tooth before cyclic loading, then each tooth was inserted into self-curing resin mold, with the long axis perpendicular to the acrylic resin base, around which was a specially fabricated split cylindrical Teflon ${ }^{\circledR}$ mold (15 mm internal diameter and $20 \mathrm{~mm}$ height).

A Lloyd LRX Plus II universal testing machine (Ametek, Inc., Berwyn, PA, USA) was used to apply occlusal cyclic loading. Each specimen was subjected to occlusal cyclic loading of $90 \mathrm{~N}$ for 5,000 cycles ${ }^{46}$ and for 10,000 cycles, in the form of a sine wave at a rate of $1 \mathrm{~Hz}$. The used rate was equal to the average cycles of mastication of $0.8-1.0$ seconds. A specially designed stainless-steel loading tip was used to apply the force on the middle of the occlusal surface of each tooth for standardization.

Table I Compositions and manufacturers of the used restorative systems

\begin{tabular}{|c|c|c|c|c|}
\hline Material & Main constituents & Manufacturer & Expiry date & Batch number \\
\hline $\begin{array}{l}\text { Xeno }{ }^{\circledR} \vee \text { (self-etching adhesive } \\
\text { system) }\end{array}$ & $\begin{array}{l}\text { Bifunctional acrylate, acidic acrylate-functionalized } \\
\text { phosphoric ester, acrylic acid, water, tertiary } \\
\text { butanol, initiator, and stabilizer }\end{array}$ & $\begin{array}{l}\text { Dentsply Caulk, } \\
\text { Milford, DE, USA }\end{array}$ & March 2015 & 0705001035 \\
\hline $\begin{array}{l}\text { BOND-I }{ }^{\circledR} \mathrm{SF} \text { (solvent-free } \\
\text { self-etching adhesive system) }\end{array}$ & $\begin{array}{l}\text { Resin matrix: UDMA, TGDMA, HEMA, 4-META, } \\
\text { and photocuring system } \\
\text { Filler: silane-treated barium glass, silica (amorphous) }\end{array}$ & $\begin{array}{l}\text { Pentron Clinical, } \\
\text { Orange, CA, USA }\end{array}$ & June 2014 & 5627 \\
\hline $\begin{array}{l}\text { Fusio }{ }^{\mathrm{TM}} \text { Liquid Dentin (self-adhesive } \\
\text { flowable composite) }\end{array}$ & $\begin{array}{l}\text { Resin matrix: 4-META-based flowable composite } \\
\text { Filler: Nano-sized amorphous silica and glass }\end{array}$ & Pentron Clinical & $\begin{array}{l}\text { November } \\
2014\end{array}$ & 02541 \\
\hline
\end{tabular}

Abbreviations: 4-META, 4-methacryloxyethyl trimellitic acid; HEMA, hydroxyethyl methacrylate; TGDMA, triethylene glycol dimethacrylate; UDMA, urethane dimethacrylate. 
Table 2 Sample groupings

\begin{tabular}{|c|c|c|c|c|c|c|c|c|c|}
\hline \multirow{2}{*}{$\begin{array}{l}\text { Adhesive } \\
\text { group } \\
\text { Subgroup }\end{array}$} & \multicolumn{3}{|c|}{$\begin{array}{l}\text { Xeno }^{\circledR} \text { V }^{\mathrm{a}} \text { with Artiste }{ }^{\circledR} \\
\text { Nano Composite }{ }^{\mathrm{b}} \text { resin }\end{array}$} & \multicolumn{3}{|c|}{$\begin{array}{l}\text { BOND- }{ }^{\circledR} \text { SF }^{\mathrm{b}} \text { with Artiste }{ }^{\circledR} \\
\text { Nano Composite resin }\end{array}$} & \multicolumn{3}{|c|}{ Fusio $^{T M}$ Liquid Dentin ${ }^{\mathrm{b}}$} \\
\hline & I & 2 & 3 & I & 2 & 3 & I & 2 & 3 \\
\hline Loading cycles & $\begin{array}{l}\text { Control } \\
\text { (no cyclic } \\
\text { loading) }\end{array}$ & $\begin{array}{l}90 \mathrm{~N} \text { for } \\
5,000 \text { cycles }\end{array}$ & $\begin{array}{l}90 \mathrm{~N} \text { for } \\
10,000 \text { cycles }\end{array}$ & $\begin{array}{l}\text { Control } \\
\text { (no cyclic } \\
\text { loading) }\end{array}$ & $\begin{array}{l}90 \mathrm{~N} \text { for } \\
5,000 \text { cycles }\end{array}$ & $\begin{array}{l}90 \mathrm{~N} \text { for } \\
10,000 \text { cycles }\end{array}$ & $\begin{array}{l}\text { Control } \\
\text { (no cyclic } \\
\text { loading) }\end{array}$ & $\begin{array}{l}90 \mathrm{~N} \text { for } \\
5,000 \text { cycles }\end{array}$ & $\begin{array}{l}90 \mathrm{~N} \text { for } \\
10,000 \text { cycles }\end{array}$ \\
\hline $\begin{array}{l}\text { Number of } \\
\text { samples }(\mathrm{N}=90)\end{array}$ & 10 & 10 & 10 & 10 & 10 & 10 & 10 & 10 & 10 \\
\hline
\end{tabular}

Notes: aManufactured by Dentsply Caulk, Milford, DE, USA; 'bmanufactured by Pentron Clinical, Orange, CA, USA.

Abbreviation: $\mathrm{N}$, newton.

\section{Nanoleakage assessment}

For nanoleakage testing, sticky wax was used to seal the root apex of each tooth, together with the whole tooth except for the restoration and a $1 \mathrm{~mm}$ margin apical to the restoration, which was then coated with two nail varnish layers. After this, teeth were immersed in 50\% silver nitrate solution for 24 hours in light-sealed container. Running water was used to rinse each specimen for 5 minutes, and then each was immersed for 8 hours in photo-developing solution while being exposed to fluorescent light to allow the silver ions to transform into metallic silver. Finally, specimens were rinsed under running water for 5 minutes to remove all traces of photo-developing solution. Longitudinal sectioning of teeth buccolingually was performed through the restoration center to be subjected to electron microscopy analysis.

Nanoleakage was assessed, in this study, using a Quanta environmental scanning electron microscope (QESEM; FEI Company, Hillsboro, OR, USA). The QESEM is an analytical device that provides a unique depth of field with minimum preparation of the specimen, as it allows the specimen to be tested with neither gold nor carbon coating. To demonstrate the presence of silver particles, energy dispersive analysis X-ray (EDAX) analysis was used. This combination provided clear images, together with accurate silver-ion penetration quantification, ${ }^{47}$ through permitting element composition analysis of the square area scanned, thus accurately identifying the existence of silver particles along the tooth-restoration interface. Scanning and EDAX quantification were performed at three fixed points on each specimen: at the middle of the cervical tooth-restoration interface, near the cavity margin, and midway between these two places.

Nanoleakage analysis results were conveyed in terms of silver deposition percentages at the three representing points, then the extent of silver penetration was calculated to work out the total silver nitrate penetration of the tested interface, which represents the most commonly used material for nanoleakage, owing to its easy migration within the interface zone as a result of its nano-scaled diameter molecule $(0.059 \mathrm{~nm}) .{ }^{18,48}$ Also, it induces a contrast that gives a clear electron microscopic picture presenting the degree of penetration into the interface. Finally it has the potential to prevent any further penetration that might occur while preparing a specimen, due to its immobilization potentiality. ${ }^{25,49}$ On the other hand, other organic dyes (including methylene blue and basic fuchsin) commonly used for evaluation of leakage have larger molecules and hence a tendency to bond to tooth structure, which can demonstrate an exaggerated gap in terms of width and depth that is larger than actually exists.

\section{Statistical analysis}

After calculation of the means and standard deviations of weight percentages of silver accumulation at the gingival margin of each group, SPSS (v 20, IBM Corporation, Armonk, NY, USA) was used for statistical analysis. The significance of the effect of adhesive systems, cyclic loading, and their interactions on nanoleakage was determined using repeated measures analysis of variance (ANOVA). In cases when the ANOVA test was significant between the mean values, Tukey's post hoc test was utilized for pair-wise comparison. The significance level was set at $P \leq 0.05$.

\section{Results}

The results revealed that adhesive systems, cyclic loading, and also the interaction between these two variables had a statistically significant effect on mean nanoleakage, as shown in Tables 3 and 4.

\section{Effect of adhesive systems}

Results showed no statistically significant difference between Xeno V self-etching adhesive and BOND-1 SF solvent-free self-etching adhesive; both showed the statistically significantly highest mean nanoleakage. Fusio Liquid Dentin showed the statistically significantly lowest mean nanoleakage, as shown in Table 5 and Figures 1-4. 
Table 3 Descriptive statistics for nanoleakage - analysis of variance results

\begin{tabular}{|c|c|c|c|}
\hline Adhesive & Cyclic loading & Mean & SD \\
\hline Xeno ${ }^{\circledast} V^{\mathrm{a}}$ (self-etching & Before & 1.88 & 0.47 \\
\hline \multirow[t]{2}{*}{ adhesive system) } & After 5,000 cycles & 4.49 & 0.57 \\
\hline & After 10,000 cycles & 5.09 & 0.72 \\
\hline BOND-I ${ }^{\circledR} \mathrm{SF}^{\mathrm{b}}$ (solvent-free & Before & 1.44 & 0.47 \\
\hline \multirow[t]{2}{*}{ self-etching adhesive system) } & After 5,000 cycles & 3.95 & 0.29 \\
\hline & After 10,000 cycles & 4.97 & 0.52 \\
\hline Fusio $^{\mathrm{TM}}$ Liquid Dentin ${ }^{\mathrm{b}}$ & Before & 0.49 & 0.23 \\
\hline (self-adhesive flowable & After 5,000 cycles & 0.54 & 0.21 \\
\hline composite) & After 10,000 cycles & 0.61 & 0.23 \\
\hline
\end{tabular}

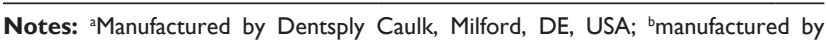
Pentron Clinical, Orange, CA, USA.

Abbreviation: SD, standard deviation.

Table 4 Effect of different variables on nanoleakage regression model results

\begin{tabular}{llllll}
\hline Source & $\begin{array}{l}\text { Type III sum } \\
\text { of squares }\end{array}$ & $\begin{array}{l}\text { df } \\
\text { square }\end{array}$ & $\begin{array}{l}\text { Mean } \\
\text { squalue }\end{array}$ & P-value \\
\hline Adhesive system & 32.2 & 2 & 16.1 & 179.2 & $<0.00 I^{*}$ \\
Cyclic loading & 42.6 & 2 & 21.3 & 131.2 & $<0.00 I^{*}$ \\
$\begin{array}{l}\text { Adhesive system } \times \\
\text { cyclic loading }\end{array}$ & 19.6 & 4 & 4.9 & 30.1 & $<0.00 I^{*}$ \\
\hline
\end{tabular}

Note: *Significant at $P \leq 0.05$.

Abbreviation: $d f$, degrees of freedom.

Table 5 Comparison between nanoleakage values with different adhesive systems

\begin{tabular}{|c|c|c|c|c|c|c|}
\hline \multicolumn{2}{|c|}{$\begin{array}{l}X{ }^{\circledR} o^{\circledR} V^{a} \\
\text { (self-etching } \\
\text { adhesive } \\
\text { system) }\end{array}$} & \multicolumn{2}{|c|}{$\begin{array}{l}\text { BOND-I }{ }^{\circledR} \text { SF }^{\mathrm{b}} \\
\text { (solvent-free } \\
\text { self-etching } \\
\text { adhesive } \\
\text { system) }\end{array}$} & \multicolumn{2}{|c|}{$\begin{array}{l}\text { Fusio }{ }^{\mathrm{TM}} \text { Liquid } \\
\text { Dentin }^{\mathrm{b}} \\
\text { (self-adhesive }_{\text {flowable }} \\
\text { composite) }\end{array}$} & \multirow[t]{2}{*}{$P$-value } \\
\hline Mean & $\overline{S D}$ & Mean & $\overline{S D}$ & Mean & SD & \\
\hline $.82^{c}$ & 1.5 & $3.45^{c}$ & 1.6 & $0.54^{d}$ & 0.21 & $<0.001 *$ \\
\hline
\end{tabular}

Notes: aManufactured by Dentsply Caulk, Milford, DE, USA; 'bmanufactured by Pentron Clinical, Orange, CA, USA. *Significant at $P \leq 0.05$, different letters (ie, $c$ and d) are statistically significantly different.

Abbreviation: SD, standard deviation.

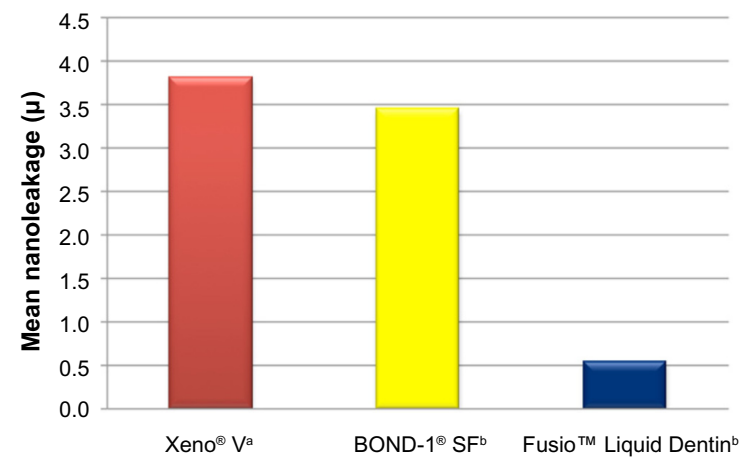

Figure I Bar chart representing comparison between mean nanoleakage.

Notes: ananufactured by Dentsply Caulk, Milford, DE, USA; 'bmanufactured by Pentron Clinical, Orange, CA, USA.

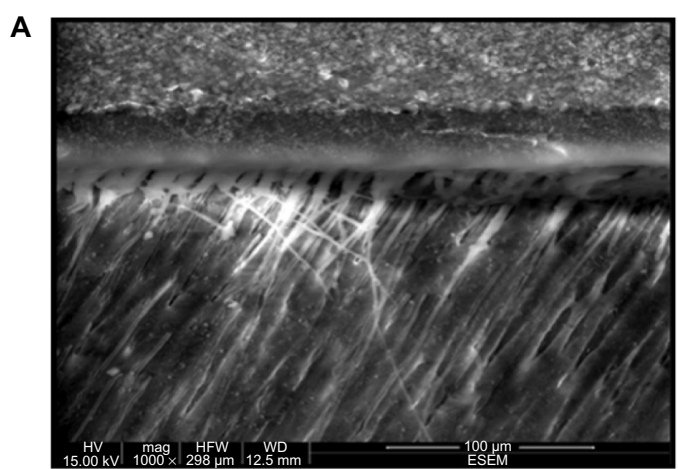

B

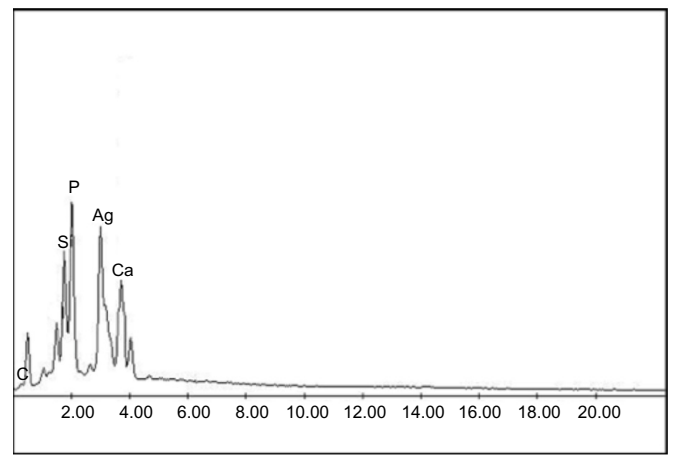

Figure 2 Scanning electron micrograph (A) and its corresponding electrondispersive analytical X-ray spectrum curve (B) at one point at the gingival toothrestoration interface representing $X e n o^{\circledR} \vee$ adhesive (self-etching adhesive system; Dentsply Caulk, Milford, DE, USA) after 5,000 load cycles.

Note: Scale bar in (A) is $100 \mu \mathrm{m}$.
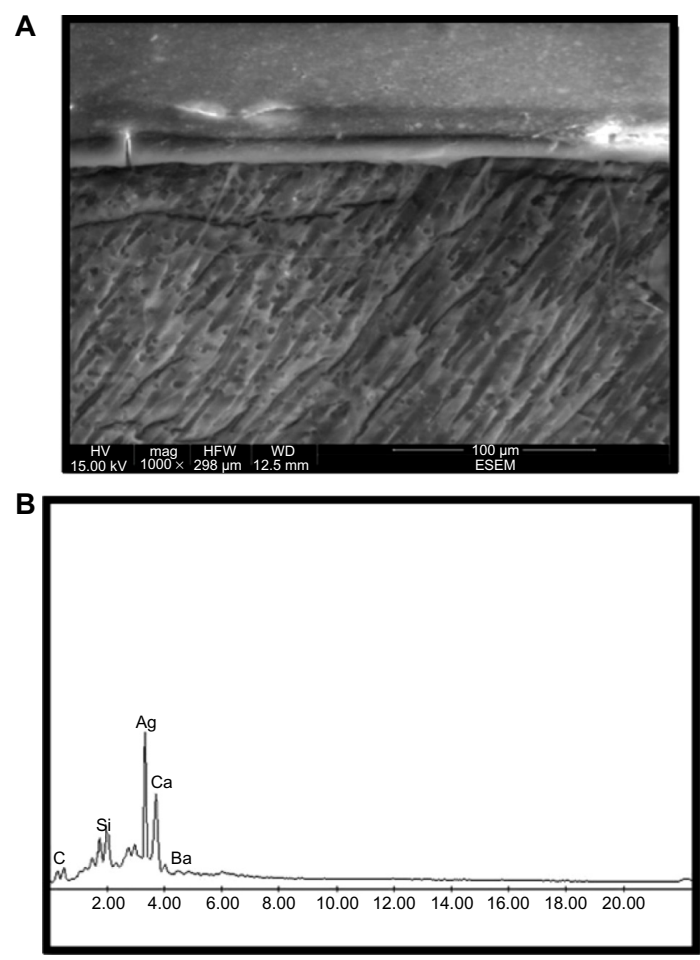

Figure 3 Scanning electron micrograph (A) and its corresponding electrondispersive analytical $\mathbf{X}$-ray spectrum curve $(\mathbf{B})$ at one point at the gingival toothrestoration interface representing BOND- $I^{\circledR} \mathrm{SF}$ (solvent-free self-etching adhesive system; Pentron Clinical, Orange, CA, USA) after 5,000 load cycles. Note: Scale bar in $(\mathbf{A})$ is $100 \mu \mathrm{m}$. 
A

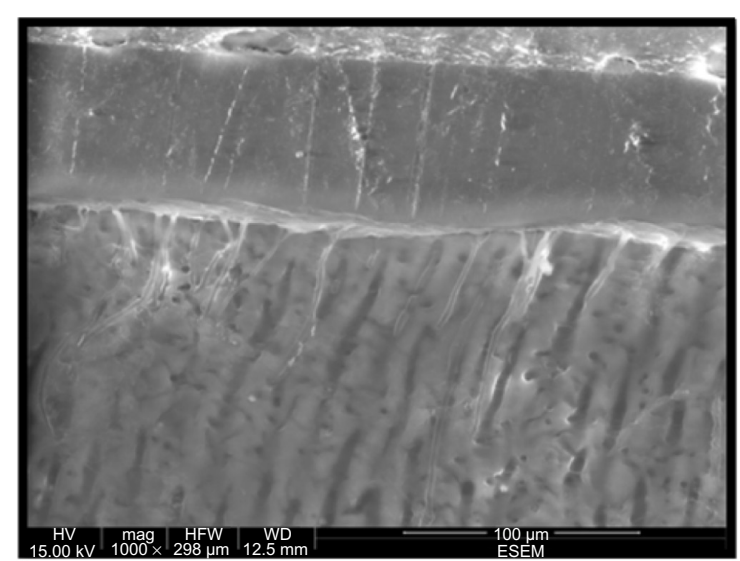

B

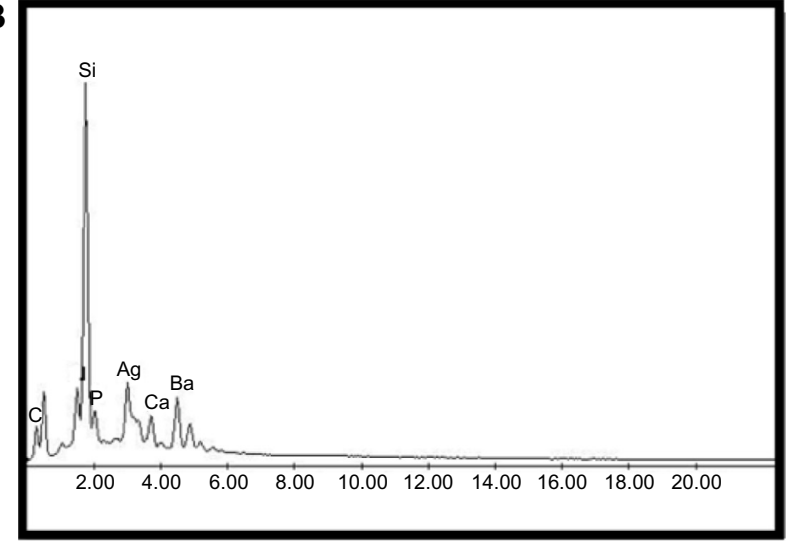

Figure 4 Scanning electron micrograph (A) and its corresponding electrondispersive analytical X-ray spectrum curve (B) at one point at the gingival toothrestoration interface representing Fusio ${ }^{\mathrm{TM}}$ Liquid Dentin (self-adhesive flowable composite; Pentron Clinical, Orange, CA, USA) after 5,000 load cycles.

Note: Scale bar in (A) is $100 \mu \mathrm{m}$.

\section{Effect of cyclic loading}

Results showed a statistically significant increase in mean nanoleakage after cyclic loading. The highest nanoleakage was found after 10,000 load cycles, as shown in Table 6 and Figure 5.

\section{Effect of different variable interactions}

Results showed no statistically significant difference between Xeno V self-etching adhesive and BOND-1 SF solvent-free self-etching adhesive after 5,000 load cycles; both showed the

Table 6 Comparison between nanoleakage values before and after cyclic loading

\begin{tabular}{|c|c|c|c|c|c|c|}
\hline \multicolumn{2}{|c|}{$\begin{array}{l}\text { Before cyclic } \\
\text { loading }\end{array}$} & \multicolumn{2}{|c|}{$\begin{array}{l}\text { After } 5,000 \\
\text { load cycles }\end{array}$} & \multicolumn{2}{|c|}{$\begin{array}{l}\text { After } 10,000 \\
\text { load cycles }\end{array}$} & \multirow[t]{2}{*}{$P$-value } \\
\hline Mean & $\overline{S D}$ & Mean & $\overline{S D}$ & Mean & $\overline{S D}$ & \\
\hline $1.27^{c}$ & 0.71 & $2.99^{b}$ & 1.85 & $3.56^{\mathrm{a}}$ & 2.21 & $<0.001^{*}$ \\
\hline
\end{tabular}

Notes: *Significant at $P \leq 0.05$, different letters $(a-c)$ are statistically significantly different.

Abbreviation: SD, standard deviation.

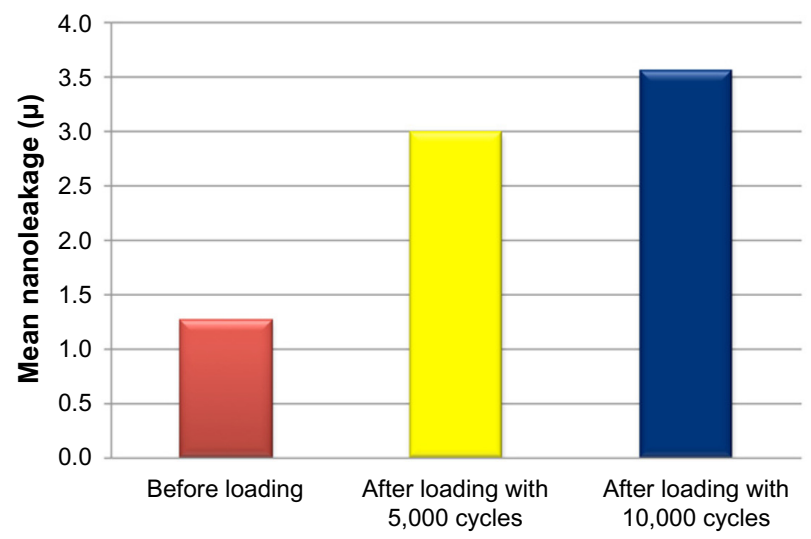

Figure 5 Bar chart representing comparison between mean nanoleakage values before and after cyclic loading.

statistically significantly highest mean nanoleakage values, as presented in Table 7 and Figure 6.

Also, results showed no statistically significant difference between Fusio Liquid Dentin before and after cyclic loading; all revealed the statistically significantly lowest mean nanoleakage values, as shown in Table 7 and Figure 6.

\section{Discussion}

The adhesive-free composites are claimed to chemically and micromechanically interact with tooth structures or other substrates, through the incorporation of an acidic adhesive monomer in their composition. ${ }^{50-52}$ They are supposed to omit any need for application of bond in a separate step, thus simplifying the restorative procedure. This is why the self-adhering flowable composite (Fusio Liquid Dentin) can be claimed to be the beginning of the eighth generation of dental adhesive systems, through the representation of a combination of flowable composite resins together with allin-one adhesive systems. ${ }^{53}$

Table 7 Comparison between nanoleakage with different interactions

\begin{tabular}{|c|c|c|c|c|}
\hline Adhesive system & Cyclic loading & Mean & SD & $P$-value \\
\hline $\mathrm{Xeno}^{\circledR} \mathrm{V}^{\mathrm{g}}$ (self-etching & Before & $1.88^{d}$ & 0.47 & $<0.00 I^{*}$ \\
\hline \multirow[t]{2}{*}{ adhesive system) } & After 5,000 cycles & $4.49^{b}$ & 0.57 & \\
\hline & After 10,000 cycles & $5.09^{a}$ & 0.72 & \\
\hline BOND-I ${ }^{\circledR} \mathrm{SF}^{\mathrm{h}}$ & Before & $\mathrm{I} .44^{\mathrm{e}}$ & 0.47 & \\
\hline (solvent-free self-etching & After 5,000 cycles & $3.95^{c}$ & 0.29 & \\
\hline adhesive system) & After 10,000 cycles & $4.97^{\mathrm{a}}$ & 0.52 & \\
\hline Fusio $^{\text {TM }}$ Liquid Dentin ${ }^{\mathrm{h}}$ & Before & $0.49^{f}$ & 0.23 & \\
\hline (self-adhesive flowable & After 5,000 cycles & $0.54^{f}$ & 0.21 & \\
\hline composite) & After 10,000 cycles & $0.6 \mathrm{I}^{\mathrm{f}}$ & 0.23 & \\
\hline
\end{tabular}

Notes: *Significant at $P \leq 0.05$, different letters $(a-f)$ are statistically significantly different. 8Manufactured by Dentsply Caulk, Milford, DE, USA; ${ }^{\text {} m a n u f a c t u r e d ~ b y ~}$ Pentron Clinical, Orange, CA, USA.

Abbreviation: SD, standard deviation. 


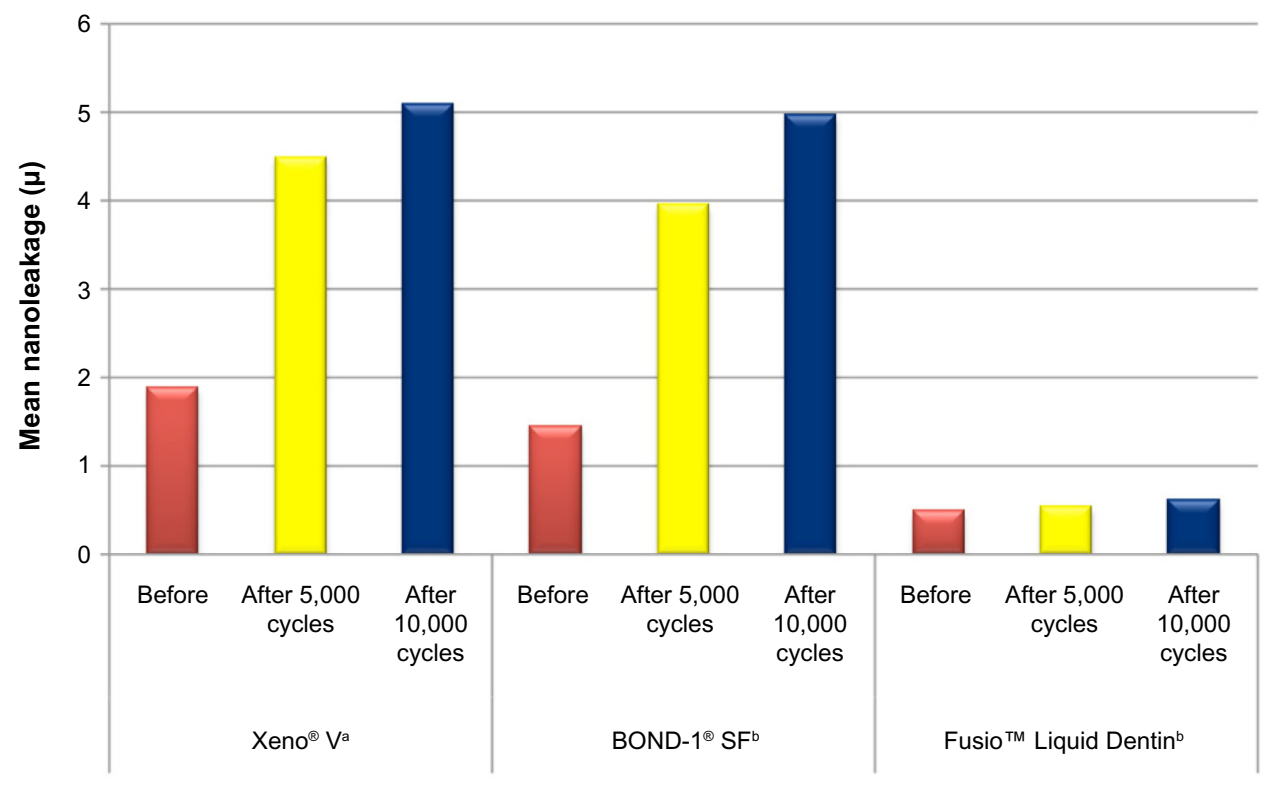

Figure 6 Bar chart representing comparison between mean nanoleakage values of different interactions.

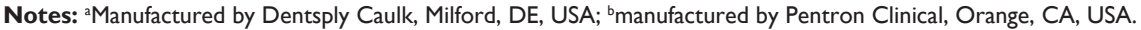

Although some authors ${ }^{35}$ have recommended that using an adhesive resin with self-adhering flowable composite resin would significantly increase dentin bond strength and reduce microleakage to both enamel and dentin, others ${ }^{54,55}$ have found that there was no significant difference detected when self adhering flowable composite was applied, according to the manufacturer's instructions, without pretreatment. Owing to the novelty of this new self-adhering flowable composite material, it seemed interesting to investigate further its sealability.

The oblique instrumental technique was used during cavity filling in this research, as it has been agreed by many authors ${ }^{53,56,57}$ that this is one of the most reliable methods to reduce the polymerization shrinkage drawbacks of composite materials, compared with other techniques such as the horizontal layering technique.

Despite the fact that clinical trials demonstrate the most reliable evidence, and the translation of in vitro findings to oral conditions has limitations, laboratory tests remain useful for promptly yielding first-hand information. ${ }^{52}$

This study aimed to assess the sealability of selfadhesive flowable composite compared with that of two adhesive systems through examining the nanoleakage of Class V composite restorations. It was found that the sealability of self-adhesive flowable composite was better, as it showed the statistically significantly lowest mean nanoleakage compared with the self-adhesive and solventfree adhesive. This was in accordance with Mobarak and Seyam, ${ }^{58}$ who found that all tested self-adhesive systems showed slight nanoleakage compared with self-etch adhesives.

This could be related to the fact that the chance for nanoleakage is higher when the demineralized dentin is deeper and the hybrid layer is thicker, as silver ions penetrate the partially or fully demineralized dentin and the hybrid layer, or also through partially polymerized adhesive resin..$^{59}$ Owing to the fact that the quantity of silver uptake per unit depth or per unit volume is the critical index of hybrid-layer quality ${ }^{60}$ and as there was no previous demineralization of dentin due to the self-adhering flowable composite, ${ }^{18}$ the depth of the demineralized dentin and the thickness of the hybrid layer was minimal compared with that of the other self-etching adhesive systems used in this research. Also, owing to the fact that selfadhering composite is flowable, it is more self-adaptable than other resin restorative materials. ${ }^{1-5}$ Furthermore, there is the possibility of less stress development in flowable composite, compared with in a hybrid one - in stiffer materials, higher polymerization stresses are created as a result of the restricted relative mobility of the formed polymer chains. ${ }^{53}$

These results, however, were not in agreement with Tay et a ${ }^{61}$ Hashimoto et al, ${ }^{62}$ and El-Badrawy et al, ${ }^{18}$ who agreed on the presence of a significant amount of nanoleakage in self-adhesive systems compared with in self-etching systems and claimed that this might be due to the incomplete polymerization of resin due to presence of residual water, which is responsible for the silver uptake, as residual water may be retained due to its low vaporization in the presence of HEMA. Finally, HEMA copolymerizes with low $\mathrm{pH}$ resin monomers 
in the presence of water, forming homologous hydrogels that allow fine silver deposits at the bonded interface. ${ }^{63}$

Although there was no statistically significant difference between the BOND-1 SF solvent-free self-etching adhesive system and Xeno V self-etching adhesive system - as they both showed the statistically significantly highest mean nanoleakage - Xeno V self-etching adhesive system showed the highest mean nanoleakage. This was found in accordance with Ferreira et al, ${ }^{64}$ who found that solvent-free adhesive showed less nanoleakage than other self-etch adhesives.

This could be attributed to the presence of HEMA in the composition of BOND-1 SF solvent-free self-etching adhesive system, in contrast to the other self-etch adhesive (Xeno $\mathrm{V}$ self-etching adhesive system) and its effect in preventing the phase separation of dental adhesive blends. ${ }^{65}$ So the hydrophobic resin component within the residual water can separate into water blisters and resin globules - so-termed resin material phase separation. ${ }^{65,66}$ Also it may be explained by the presence of water in the Xeno $\mathrm{V}$ composition (leading to water sorption), and incorrect organic solvent evaporation. ${ }^{64}$

This study aimed to assess the aging of tested materials in terms of cyclic loading. It was found that examined materials' aging, in terms of cyclic loading, increased nanoleakage significantly in all tested groups. This was in accordance with Kubo et $a l^{67}$ and Swathi et al, ${ }^{68}$ who stated that nanoleakage of composite restorations occurs because of stress placed along the tooth-restoration interface due to various factors, such as polymerization shrinkage, thermo-cycling in the oral environment, and mechanical fatigue through repetitive masticatory loading. Also, our findings are in agreement with Ameri et $\mathrm{al}^{38}$ and Bedran-de-Castro et $\mathrm{al},{ }^{43}$ who concluded that cyclic loading increased nanoleakage of the margins of Class V composite restorations.

However, our results were not in accordance with Yamazaki et al, ${ }^{69}$ who stated that the application of mechanical cyclic loading did not increase nanoleakage.

The diversities in the reported data could be attributed to dissimilarities between preparation types and sizes; operator variability; materials used; and load cycle values, direction, and number. ${ }^{38,70}$ On the other hand, a limitation of this study is that it was carried out in laboratory conditions, negating the effect of pulpal pressure on the used restorative systems. Thus, more clinical evaluations should be carried out as such in vitro studies do not eliminate the need for clinical ones.

\section{Conclusion}

Under the test conditions, the self-adhesive flowable composite provided better sealability in terms of nanoleakage when compared with different one-step self-etching bonding systems used in combination with a hybrid composite. Also, cyclic loading increased nanoleakage in all tested materials.

\section{Disclosure}

The authors report no conflicts of interest in this work.

\section{References}

1. Miyasaka T, Okamura H. Dimensional change measurements of conventional and flowable composite resins using a laser displacement sensor. Dent Mater J. 2009;28(5):544-551.

2. Yazici AR, Celik C, Dayangac B, Ozgunaltay G. Effects of different light curing units/modes on the microleakage of flowable composite resins. Eur J Dent. 2008;2:240-246.

3. Attar N, Tam LE, McComb D. Flow, strength, stiffness and radiopacity of flowable resin composites. J Can Dent Assoc. 2003;69(8):516-521.

4. Kleverlaan CJ, Feilzer AJ. Polymerization shrinkage and contraction stress of dental resin composites. Dent Mater. 2005;21(12): $1150-1157$.

5. Qin M, Liu H. Clinical evaluation of a flowable resin composite and flowable compomer for preventive resin restorations. Oper Dent. 2005;30(5):580-587.

6. Unterbrink GL, Liebenberg WH. Flowable resin composites as "filled adhesives": literature review and clinical recommendations. Quintessence Int. 1999;30(4):249-257.

7. Manhart J, Chen HY, Mehl A, Weber K, Hickel R. Marginal quality and microleakage of adhesive class V restorations. J Dent. 2001;29(2): 123-130.

8. Sensi LG, Marson FC, Monteiro S Jr, Baratieri LN, Caldeira de Andrada MA. Flowable composites as "filled adhesives": a microleakage study. J Contemp Dent Pract. 2004;5(4):32-41.

9. Jang KT, Chung DH, Shin D, García-Godoy F. Effect of eccentric load cycling on microleakage of Class $\mathrm{V}$ flowable and packable composite resin restorations. Oper Dent. 2001;26(6):603-608.

10. Xie H, Zhang F, Wu Y, Chen C, Liu W. Dentine bond strength and microleakage of flowable composite, compomer and glass ionomer cement. Aust Dent J. 2008;53(4):325-331.

11. Braga RR, Hilton TJ, Ferracane JL. Contraction stress of flowable composite materials and their efficacy as stress-relieving layers. $J \mathrm{Am}$ Dent Assoc. 2003;134(6):721-728.

12. Chimello DT, Chinelatti MA, Ramos RP, Palma Dibb RG. In vitro evaluation of microleakage of a flowable composite in Class V restorations. Braz Dent J. 2002;13(3):184-187.

13. Cardoso PE, Braga RR, Carrilho MR. Evaluation of micro-tensile, shear and tensile tests determining the bond strength of three adhesive systems. Dent Mater. 1998;14(6):394-398.

14. Swift EJ Jr, Perdigão J, Heymann HO. Bonding to enamel and dentin: a brief history and state of the art, 1995. Quintessence Int. 1995;26(2): 95-110.

15. Hannig M, Friedrichs C. Comparative in vivo and in vitro investigation of interfacial bond variability. Oper Dent. 2001;26(1):3-11.

16. Haller B. Recent developments in dentin bonding. Am J Dent. 2000;13(1):44-50.

17. Osorio R, Toledano M, de Leonardi G, Tay F. Microleakage and interfacial morphology of self-etching adhesives in class $\mathrm{V}$ resin composite restorations. J Biomed Mater Res B Appl Biomater. 2003;66(1): 399-409.

18. El-Badrawy W, Hafez RM, El Naga AI, Ahmed DR. Nanoleakage for Self-Adhesive Resin Cements used in Bonding CAD/CAD Ceramic Material to Dentin. Eur J Dent. 2011;5(3):281-290.

19. Eick JD, Welch FH. Polymerization shrinkage of posterior composite resins and its possible influence on postoperative sensitivity. Quintessence Int. 1986;17(2):103-111. 
20. Krejci I, Lutz F. Marginal adaptation of Class V restorations using different restorative techniques. $J$ Dent. 1991;19(1):24-32.

21. Sano H, Shono T, Takatsu T, Hosoda H. Microporous dentin zone beneath resin-impregnated layer. Oper Dent. 1994;19(2):59-64.

22. Andia-Merlin RY, Garone-Netto N, Arana-Chavez VE. SEM evaluation of the interaction between a three-step adhesive and dentin. Oper Dent. 2001;26(5):440-444.

23. Vaidyanathan TK, Vaidyanathan J. Recent advances in the theory and mechanism of adhesive resin bonding to dentin: a critical review. J Biomed Mater Res B Appl Biomater. 2009;88(2):558-578.

24. Eick JD, Gwinnett AJ, Pashley DH, Robinson SJ. Current concepts on adhesion to dentin. Crit Rev Oral Biol Med. 1997;8(3):306-335.

25. Li H, Burrow MF, Tyas MJ. Nanoleakage patterns of four dentin bonding systems. Dent Mater. 2000;16(1):48-56.

26. Sano H, Takatsu T, Ciucchi B, Horner JA, Matthews WG, Pashley DH. Nanoleakage: leakage within the hybrid layer. Oper Dent. 1995;20(1): $18-25$.

27. Dhanyakumar S. Comparative evaluation of micro-shear bond strength of adhesive resins to coronal dentin versus dentin at floor of pulp chamber - an in vitro study. $J$ Conserv Dent. 2006;9(4):123-130.

28. Tay FR, Pashley DH. Aggressiveness of contemporary self-etching systems. I: Depth of penetration beyond dentin smear layers. Dent Mater. 2001;17(4):296-308.

29. Hegde MN, Hegde P, Chandra CR. Morphological evaluation of new total etching and self etching adhesive system interfaces with dentin. $J$ Conserv Dent. 2012;15(2):151-155.

30. Vichi A, Margvelashvili M, Goracci C, Papacchini F, Ferrari M. Bonding and sealing ability of a new self-adhering flowable composite resin in class I restorations. Clin Oral Invest. 2013;17(6):1497-1506.

31. Eliades G, Vougiouklakis G, Palaghias G. Heterogeneous distribution of single-bottle adhesive monomers in the resin-dentin interdiffusion zone. Dent Mater. 2001;17(4):277-283.

32. Koliniotou-Koumpia E, Kouros P, Koumpia E, HelvatzoglouAntoniades M. Shear bond strength of a "solvent-free" adhesive versus contemporary adhesive systems. Brazilian Journal of Oral Sciences. 2014;13(1):64-69.

33. Yoshida Y, Nagakane K, Fukuda R, et al. Comparative study on adhesive performance of functional monomers. J Dent Res. 2004;83(6):454-458.

34. Sadeghi M. An in vitro microleakage study of class $V$ cavities restored with a new self-adhesive flowable composite resin versus different flowable materials. Dent Res J (Isfahan). 2012;9(4):460-465.

35. Bektas OO, Eren D, Akin EG, Akin H. Evaluation of a self-adhering flowable composite in terms of micro-shear bond strength and microleakage. Acta Odontol Scand. 2013;71(3-4):541-546.

36. Poss SD. Utilization of a new self-adhering flowable composite resin Dent Today. 2010;29(4):104-105.

37. Kerr Sybron Dental Specialties. Vertise Flow: Self-Adhering Flowable Composite. Technical Bulletin. Orange, CA: Kerr Sybron Dental Specialties; 2010. Available from: http://www.kerrdental.com/ cms-filesystem-action/KerrDental-products-techinfo/vertiseflow_ techbulletin_34929b.pdf. Accessed January 28, 2015.

38. Ameri H, Chasteen JE, Ghavamnasiri M, Maghami A. Effect of load cycling on nanoleakage of butt joint and beveled occlusal enamel margins in Class V composite resin restorations. Revista de Clínica e Pesquisa Odontológica [Journal of dental clinics and research]. 2010;6(3):231-237.

39. McCoy G. The etiology of gingival erosion. J Oral Implantol. 1982; 10(3):361-362.

40. Darendeliler S, Darendeliler H, Kinoğlu T. Analysis of a central maxillary incisor by using a three dimensional finite element method. J Oral Rehabil. 1992;19(4):371-383.

41. Van Meerbeek B, Braem M, Lambrechts P, Vanherle G. Evaluation of two dentin adhesives in cervical lesions. J Prosthet Dent. 1993;70(4): 308-314.

42. Miranda WG Jr, Nunes MF, Cardoso PE, Santos JF. Microleakage of condensable composite resins combined with a flowable composite. J Dent Res. 1999;78 (special issue):Abstract 1603:306.
43. Bedran-de-Castro AK, Pereira PN, Pimenta LA, Thompson JY. Effect of thermal and mechanical load cycling on nanoleakage of Class II restorations. J Adhes Dent. 2004;6(1):221-226.

44. Radovic I, Vulicevic ZR, García-Godoy F. Morphological evaluation of 2- and 1-step self-etching system interfaces with dentin. Oper Dent. 2006;31(6):710-718.

45. Van Meerbeek B, Peumans M, Poitevin A, et al. Relationship between bond-strength tests and clinical outcomes. Dent Mater. 2010;26(2): e100-e121.

46. Li H, Burrow MF, Tyas MJ. The effect of load cycling on the nanoleakage of dentin bonding systems. Dent Mater. 2002;18(2):111-119.

47. Yuan Y, Shimada Y, Ichinose S, Tagami J. Qualitative analysis of adhesive interface nanoleakage using FE-SEM/EDS. Dent Mater. 2007; 23(5):561-569.

48. Ibarra G, Johnson GH, Geurtsen W, Vargas MA. Microleakage of porcelain veneer restorations bonded to enamel and dentin with a new self-adhesive resin-based dental cement. Dent Mater. 2007;23(2): 218-225.

49. Pioch T, Staehle HJ, Duschner H, García-Godoy F. Nanoleakage at the composite-dentin interface: a review. Am J Dent. 2001;14(4): $252-258$.

50. Fu J, Kakuda S, Pan F, et al. Bonding performance of a newly developed step-less all-in-one system on dentin. Dent Mater J. 2013;32(2): 203-211.

51. Juloski J, Goracci C, Rengo C, et al. Enamel and dentin bond strength of new simplified adhesive materials with and without preliminary phosphoric acid-etching. Am J Dent. 2012;25(4):239-243.

52. Garcia RN, Morelli AE, Giongo BM, et al. Bonding performance of a self-adhering flowable composite to substrates used in direct technique. Revista Sul-Brasileira de Odontologia [South Brazilian dentistry journal]. 2013;10(4):343-349.

53. Vichi A, Goracci C, Ferrari M. Clinical study of the self-adhering flowable composite resin Vertise Flow in Class I restorations: six-month follow-up. International Dentistry (South Africa). 2011;2(1):44-51.

54. Rengo C, Goracci C, Juloski J, et al. Influence of phosphoric acid etching on microleakage of a self-etch adhesive and a self-adhering composite. Aust Dent J. 2012;57(2):220-226.

55. Gönülol N, Ertan Ertaş E, Yılmaz A, Çankaya S. Effect of thermal aging on microleakage of current flowable composite resins. J Dent Sci. Epub June 5, 2014.

56. Nikolaenko SA, Lohbauer U, Roggendorf M, Petschelt A, Dasch W, Frankenberger R. Influence of $\mathrm{C}$-factor and layering technique on microtensile bond strength to dentin. Dent Mater. 2004;20:579-585.

57. Tsai PC, Meyers IA, Walsh LJ. Depth of cure and surface microhardness of composite resin cured with blue LED curing lights. Dent Mater. 2004;20(4):364-369.

58. Mobarak E, Seyam R. Interfacial nanoleakage and bonding of selfadhesive systems cured with a modified-layering technique to dentin of weakened roots. Oper Dent. 2013;38(5):E154-E165.

59. Pereira PN, Okuda M, Nakajima M, Sano H, Tagami J, Pashley DH. Relationship between bond strengths and nanoleakage: evaluation of a new assessment method. Am J Dent. 2001;14(2):100-104.

60. Lee TY, Cho BH, Son HH. The nanoleakage patterns of different dentin adhesive systems. Taehan Ch ikwa Pojon Hakhoe chi [Journal of Korean Academy of Conservative Dentistry]. 2003;28(2):169-177.

61. Tay FR, Pashley DH, Yoshiyama M. Two modes of nanoleakage expression in single-step adhesives. $J$ Dent Res. 2002;81(7):472-476.

62. Hashimoto M, Ohno H, Sano H, Kaga M, Oguchi H. Degradation patterns of different adhesives and bonding procedures. J Biomed Mater Res B Appl Biomater. 2003;66(1):324-330.

63. Tay FR, King NM, Chan KM, Pashley DH. How can nanoleakage occur in self-etching adhesive systems that demineralize and infiltrate simultaneously? J Adhes Dent. 2002;4(4):255-269.

64. Ferreira JC, Pires PT, Azevedo AF, Oliveira SA, Melo PR, Silva MJ. Influence of solvents and composition of etch-and-rinse and self-etch adhesive systems on the nanoleakage within the hybrid layer. J Contemp Dent Pract. 2013;14(4):691-699. 
65. Spencer P, Wang Y. Adhesive phase separation at the dentin interface under wet bonding conditions. J Biomed Mater Res. 2002;62(3): $447-456$.

66. Tay FR, Gwinnett JA, Wei SH. Micromorphological spectrum from overdrying to overwetting acid-conditioned dentin in water-free acetone-based, single-bottle primer/adhesives. Dent Mater. 1996;12(4): 236-244.

67. Kubo S, Yokota H, Sata Y, Hayashi Y. The effect of flexural load cycling on the microleakage of cervical resin composites. Oper Dent. 2001;26(5):451-459.
68. Swathi L, Akkala SR, Thomas T, Veronica. Nanoleakage evaluation of a silorane based, nanohybrid and giomer composites - an in-vitro study. International Organization of Scientific Research Journal of Dental and Medical Sciences. 2014;13(1):62-64.

69. Yamazaki PC, Bedran-Russo KB, Pereira PNR. The effect of load cycling on nanoleakage of deproteinized resin/dentin interfaces as a function of time. Dent Mater. 2004;24(7):867-873.

70. Mandras RS, Retief DH, Russell CM. The effects of thermal and occlusal stresses on the microleakage of the Scotchbond 2 dentinal bonding system. Dent Mater. 1991;7(1):63-70.

\section{Publish your work in this journal}

Clinical, Cosmetic and Investigational Dentistry is an international, peer-reviewed, open access, online journal focusing on the latest clinical and experimental research in dentistry with specific emphasis on cosmetic interventions. Innovative developments in dental materials, techniques and devices that improve outcomes and patient satisfaction and preference will be highlighted. The manuscript management system is completely online and includes a very quick and fair peerreview system, which is all easy to use. Visit http://www.dovepress. com/testimonials.php to read real quotes from published authors.

Submit your manuscript here: http://www.dovepress.com/clinical-cosmetic-and-investigational-dentistry-journal 